\title{
Special Gastrointestinal Lesions Caused by Acute Diquat Poisoning
}

\author{
Hongxia Bi, Haibo Tang and $\mathrm{Yu} \mathrm{Du}^{*}$ \\ Emergence department and intensive care unit, West China School of Public Health, China
}

Received: April 10, 2018; Published: May 08, 2018

*Corresponding author: Yu Du, Emergence department and intensive care unit, west China School of Public Health, West China Teaching Hospital, Sichuan University, Chengdu, China

\section{Abstract}

A 24-years-old male with massive diquat ingestion complicated by the development of gastrointestinal ulcer perforation, intestinal hyperpiesia, liver failure, renal failure is described. The patient ultimately dead from serious complications. The rare and special gastrointestinal lesions after acute diquat poisoning is worth for us to explore.

Keywords: Diquat; Poisoning; Special Gastrointestinal Lesions

\section{Introduction}

Diquat $\left(1,1^{\prime}\right.$-ethylene-2,2'-bipyridilium) is a non-selective bipyridyl herbicide similar to paraquat [1]. Since the paraquat solution was banned in China since September 7, 2016, the diquat has gradually become a major substitute for the herbicide market [2]. Although there are far less case reports in the literature than paraquat poisoning, it is likely to become an potential threat of pesticide poisoning in the near future. There are different complications between diquat and paraquat. Paraquat mainly cause lung injury, and ultimately died from respiratory failure, however, the manifestation of diquat poisoning is gastrointestinal tract [3]. As with paraquat, most of the fatalities involved ingestion of the concentrated formulation with suicidal intent.

\section{Case Report}

A 24 years old young man without any medical history attempted suicideby ingesting about a bottle of pesticide with "weed killer" label (analytical grade20\% diquat $100 \mathrm{ml}$ ) at approximately 00:20 on October 20th.Five minutes after ingestion, the patient began vomiting with much of green gastric contents. After 2 hours, he was taken to local county hospital, giving lavage gastric, inhibiting gastric acid, protecting liver, andso on. The patient was presented to our hospital to get better treatment at 11:20 on October $20^{\text {th }}$. On admission, he was conscious and without abdominal pain, vital signs were as follows: pulse rate 104 beats/min regular, blood pressure 126/79mmHg, respiratory rate 25 breaths/min, and arterial oxygen saturation $99 \%$ on oxygen concentration $3 \mathrm{~L} / \mathrm{min}$. Physical examination was otherwise unremarkable. He was given $30 \mathrm{~g}$ of activated charcoal and montmorillonite, following by vomiting brownish-blackish gastric contents. 500mg methylprednisolone was given every 12 hours. A qualitative urine test (dithionite test) which is normally used for paraquat was negative, analysis of blood sample confirmed that paraquat was not detected. Diuresis was given to maintain urine output at least $>100 \mathrm{ml} /$ hour. 12 hours after ingestion, the laboratory investigation is shown in Table 1.

Table 1: Laboratory investigations (normal range in parentheses).

\begin{tabular}{|c|c|c|}
\hline Analyte & $\mathbf{1}$ hour & $\mathbf{3 0}$ hours \\
\hline Full blood count & & \\
\hline Hemoglobin(120-160g/L) & 144 & 154 \\
\hline White cell count $\left(4-10 \times 10^{9} / \mathrm{L}\right)$ & 18.2 & 15.4 \\
\hline Platelets(100-300×10 $/ \mathrm{L})$ & 118 & 90 \\
\hline Alanine aminotransaminase (9-50 U/L) & 137 & 1145 \\
\hline Aspartate aminotransaminase (15-40 U/L) & 193 & 1511 \\
\hline Total bilirubin $(0-28 \mathrm{umol} / \mathrm{L})$ & 16.6 & 8.7 \\
\hline Albumin (40-55 g/L) & 42.0 & 36.9 \\
\hline Urea (1.7-8.3 mmol/L) & 7.2 & 16.95 \\
\hline Creatinine (40-133 umol/L) & 204.1 & 470.3 \\
\hline Creatine kinase (25-200 U/L) & 1826 & 19835 \\
\hline Globulin (3.5-6 mmol/L) & 6.37 & 7.44 \\
\hline Sodium (137-147 mmol/L) & 134 & 133 \\
\hline Potassium (3.5-5.3 mmol/L) & 4.20 & 5.51 \\
\hline Phosphorus (0.8-1.6 mmol/L) & 0.47 & 3.23 \\
\hline Arterial blood gases (oxygen 3L/min) & & \\
\hline pH (7.35-7.45) & 7.35 & 7.26 \\
\hline Carbon dioxide pressure(35-48mmHg) & 31 & 56 \\
\hline Oxygen pressure(83-108mmHg) & 135 & 74 \\
\hline Oxygen saturation (95\%-99\%) & 98.9 & 77 \\
\hline
\end{tabular}


He was started hemoperfusion with 2 hours to eliminate toxin at 12:50 on October $20^{\text {th }}$. After finished hemoperfusion, the patient began to disorderly speak, but hadn't normally behavior and nonconsciousness. The patient has finished second hemoperfusion at 23:50 on October $20^{\text {th }}$, his general deteriorated. He became agitated and pulled out femoral vein catheter by himself. He felt abdominal pain, bowels couldn't be moved. Abdomen examination was swelling, muscle tension rising, and total abdominal tenderness, bowel sounds weaken. Chest examination was normal. Taken for intestinal obstruction, the patient was given parenteral diazepam, forbidden eat and drink. But the patient was still very agitated, refused to arrange stomach tube. Vital signs showed blood pressure 114/63mmHg, radial pulse 96 beats/min, and respiratory rate 20 beats/min. Chest radiography showed ill defended bilateral lung changes of possible infection (Figure 1). Abdomen radiography showed that much of gas deposited in the esophageal, stomach, intestinal, liver, pancreas, and right groin area (Figure 1).



Figure 1: $A B=$ Bilateral pulmonary multiple nodular change, probable infection. $C, D=$ stomach, intestinal, liver, pancreas and renal multiple pneumatosis.

After 2 hours with above therapy, the patients became much more agitated and nonconscious, with nausea, vomiting, shortness of breath. Abdominal muscle tension was too higher than before to touch, with intestinal sound disappeared. 30 hours after ingestion, laboratory investigations are shown in Table 1 . His renal and liver function continued to deteriorate, blood gases deteriorated shadowing in both lung fields and renal function. After repeated account with his family members, his parents decided to give up all therapy, including endotracheal intubation and blood purification. At 11:05 on October $21^{\text {th }}$, the patient's state continued to deteriorate, vomited a lot of green gastric contents, lost consciousness, blood pressure decreased to $50 / 23 \mathrm{mmHg}$, and oxygen saturation $87 \%$. Because his patients have given up all therapy, the doctor did not give drugs and mechanical ventilation, the patient dead ultimately at $11: 30$ on October $21^{\text {th }}$.

\section{Discussion}

Paraquat and diquat are bipyridyl herbicides, which them are inactivated by adsorption to clay material in the soil [4]. Due to the severely toxicity, the paraquat solution had been prohibited to manufacture and sales in china since July 1,2016. But as agricultural country, many factories use diquat instead of paraquat to production.
Unlike paraquat, diquat is not selectively concentrated in the lung and is not known to directly cause pulmonary fibrosis [5].

With an oral LD50 of $231 \mathrm{mg} / \mathrm{kg}$ in rats [6], diquat is a potent redox cycler and is converted to a free radical which in reaction with molecular oxygen, generates superoxide anions and subsequently other redox products.These products can induce lipid peroxidation in cell membranes, and cause cell death. Another contributing factor of toxicity is the depletion of nicotinamide adenine dinucleotide phosphate with bound hydrogen ion (NADPH) $[1,6]$.

Alarge number of paraquat poisonings have been reported, while the number of reported diquat poisonings is comparatively small. In mild and moderate to severe poisoning, the clinic manifestation of diquat is essentially the similar to paraquat, difference in pulmonary fibrosis and refractory hypoxemia of paraquat poisoning. However, the clinical manifestation of this patient is relatively rare, for fulminant poisoning, massive intestinal fluid loss, hypovolemic shock, gastrointestinal ulcers, especially perforation causing from intestinal high pressure in diquat poisoning. As the patient, few hours after ingestion, he began to appear apparent abdominal distension, vomiting, symptoms of ileus, CT scan-abdomen shown multiple organs pneumatosis. Previous reports, abdominal imaging diquat-induced almost be reported due to serious illness. In our report, the accumulation of multiple organs in the abdominal cavity was caused by gastrointestinal mucosal injury, which leads to the entry of gas into the organs through the portal vein system. This may be different from paraquat poisoning. There is not show severe chemical injury in the lung of this patient, however, the above gastrointestinal change caused by the strong corrosion effect of diquat is one of the leading causes of death. So far, there is no specific antidote to the treatment of diquat poisoning, mostly treatment principle is more reference to paraquat poisoning, with preventing absorption and enhanced elimination.

Gastric lavage, the use of activated charcoal and mannitol have been advocated as an early treatment to reduce absorption. Because of massive intestinal fluid loss, lots of liquid should be inputted to maintain enough blood vessel capacity and renal perfusion, particularly when treatment is delayed [1,7]. Due to toxin-induced gastrointestinal mucosal erosion, intestinal obstruction usually happens, so patient once feel abdominal distention, gastrointestinal decompression would better be given early. For our patient, because of ingesting larger doses of diquat, and its corrosive action to mucosa, gastrointestinal decompression failed, ultimately, the patient died of hypovolemic shock due to massive gastrointestinal fluid loss. As with paraquat, hemoperfusion should be given as soon as possible, although the effect is not definite so far. Hemodialysis was found to be ineffective in removing diquat from the circulation [8]. When occurring renal failure, continuous renal replacement therapy may be effective to help toxins excreted and maintain the electrolyte balance.

As with paraquat poisoning, mortality of diquat-induced is quietly high, depending on ingesting dose, admission time, properly treatment. We look forward to more research on the mechanism and specific treatment of the diquat poisoning. In addition,toxic 
chemicals strictly control is still essential laws and regulations. Psychiatric prevention for most of thepoisonings among highrisk population is no less important than the available medical treatment.

\section{References}

1. Jones GM, Vale JA (2000) Mechanisms of toxicity, clinical features, and management of diquat poisoning: a review. J Toxicol Clin Toxicol 38(2):123-128.

2. Administration of the Ministry of Agriculture Planting. Announcement of the Ministry of Agriculture of the People's Republic of China: NO 2445.2016.9.7 00:00.

3. Litchfield MH, Daniel JW, Lonqshaw S (1973) The tissue distribution of the bipyridylium herbicides diquat and paraquat in rats and mice. Toxicology 1(2): 155 -165.

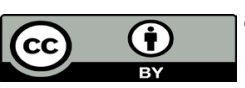

This work is licensed under Creative Commons Attribution 4.0 License

Submission Link: https://biomedres.us/submit-manuscript.php
4. Conning DM, Fletcher K, Swann A (1969) Paraquat and related bipyridyls. Br Med Bull 25(3): 245-249.

5. Fortenberry GZ, Beckman J, Schwartz A, Prado JB, Graham LS, et al. (2016) Magnitude and characteristics of acute paraquat- and diquatrelated illnesses in the US: 1998-2013. Environ Res 146: 191-199.

6. (2005) World Health Organization 2005, The WHO Recommended Classification of Pesticides by Hazard and Guidelines to Classification 2004. International Programme on Chemical Safety.

7. Vanholder R, Colardyn F, De Reuck J, Praet M, Lameire N, et al. (1981) Diquat intoxication. Report of two cases and review of the literature. Am J Med 70(6):1267 -1271.

8. Okonek S, Hofmann A (1975) Extracorporeal hemodialysis in diquat intoxication. Arch Toxicol 33: 251-257.



